\title{
The value of effective public tuberculosis treatment: an analysis of opportunity costs associated with multidrug resistant tuberculosis in Latvia
}

\author{
Thaddeus L Miller ${ }^{* *}$, Andra Cirule², Fernando A Wilson ${ }^{1}$, Timothy H Holtz ${ }^{3}$, Vija Riekstina², Kevin P Cain ${ }^{4}$,
} Patrick K Moonan ${ }^{4}$ and Vaira Leimane ${ }^{5}$

\begin{abstract}
Background: A challenge to effective protection against tuberculosis is to sustain expensive and complex treatment public programs. Potential consequences of program failure include acquired drug resistance, poor patient outcomes, and potentially much higher system costs, however. In contrast, effective efforts have value illustrated by impacts they prevent. We compared the healthcare costs and treatment outcomes among multidrugresistant tuberculosis (MDR-TB) and non MDR-TB patients in Latvia to identify benefits or costs associated with both.

Methods: We measured and compared costs, healthcare utilization, and outcomes for patients who began treatment through Latvia's TB control program in 2002 using multivariate regression analysis and negative binomial regression.

Results: We analyzed data for 92 MDR-TB and 54 non MDR-TB patients. Most (67\%) MDR-TB patients had history of prior tuberculosis treatment. MDR-TB was associated with lower cure rates (71\% vs. 91\%) and greater resource utilization. MDR-TB treatment cost almost $\$ 20,000$ more than non MDR-TB.
\end{abstract}

Conclusion: Up to 2/3 of MDR-TB treated in our sample was preventable at a potential savings of over $\$ 1.3$ million in healthcare resources as well as substantial individual health.

Keywords: Tuberculosis cost, Health economics, Cost analysis, Evidence based policy

\section{Background}

Tuberculosis control poses significant challenges despite existing highly successful, relatively inexpensive treatment $[1,2]$. A principal challenge is duration-usually no less than 6 months-of chemotherapy, which contributes to nonadherence, treatment failure, and-if not completed-the acquisition of anti-tuberculosis drug resistance [1-3]. Consistent and thorough management of tuberculosis by health authorities using the World Health Organization's widely adopted DOTS strategy is key to avoiding treatment failure and its consequences [4-9]. Evidence links treatment failure and its consequences to insufficient management of active

\footnotetext{
* Correspondence: thaddeus.miller@unthsc.edu

'University of North Texas Health Science Center at Fort Worth, School of Public Health, Fort Worth, TX, USA

Full list of author information is available at the end of the article
}

tuberculosis. Still, robust tuberculosis control programs are often not priority for public investment $[10,11]$.

Effective and sustained tuberculosis control and achievement of elimination goals is possible through public health system efforts and the population-based infrastructure they provide. Many health needs exist, however, and policy makers often lack evidence to objectively identify priority among them. Cost and outcome analysis can provide useful evidence to guide decision makers toward supporting the "most effective medical care affordable" [12].

It is increasingly important to quantify the economic value of effective tuberculosis control in order to justify, prioritize, and sustain public investments toward it [13,14]. Health, economic, and other losses may be especially substantial in drug-resistant tuberculosis. Cure of drugresistant, and especially MDR-TB is less likely, and requires 
more toxic and expensive treatment $[3,15,16]$. Yet acquired drug resistance can be prevented. Consistent use of best practices in tuberculosis management, such as prompt diagnosis, including drug susceptibility testing and direct observation of therapy, may be expensive yet cheaper than the alternative.

Budget constraints can be acute in regions such as Eastern Europe as they move beyond the economic and political turmoil left after the dissolution of the former Soviet Union (FSU). Latvia is one such nation, and like many of its neighbors has a high burden of tuberculosis and a significant incidence of MDR-TB (Table 1). Latvia reported MDR-TB prevalence of $14.3 \%$ and $10 \%$ in 2008 and 2009 respectively [10]. This is in comparison to a median prevalence of $9 \%$ (range: $1.6 \%-22.3 \%$ ) for 26 other high burden countries [17].

The fall of the Soviet Union left Latvia's health care system in disarray. TB diagnosis was disorganized and treatment haphazard. Treatment interruption, largely due to erratic drug supply, was one of the main drivers of the rise of drug-resistant tuberculosis during the unsteady 1990s [18]. High rates of MDR-TB identified 1994 prompted subsequent adoption of the DOTS-Plus strategy, with systematic response to drug resistance becoming standard [19]. As a result, Latvia has seen declining incidence and prevalence of MDR-TB [19,20]. We compared treatment costs and outcomes among MDR-TB and non MDR-TB patients in Latvia to partially identify the value of these investments.

\section{Methods}

We retrospectively compared patients with identified MDR-TB to those with non MDR-TB to identify differences in health system cost stratified by patient outcomes. Latvia's national tuberculosis control program, the Nacionala Tuberkulozes Apkarošanas Programma (NTAP) treats tuberculosis patients and provides other public health protections as well; the NTAP and its activities are well described elsewhere $[18,19]$. We obtained study data from NTAP's national tuberculosis registry and patient medical records.

Study subjects received all tuberculosis treatment through Latvia's TB control program. Records for all nonimprisoned, tuberculosis patients aged $>=18$ with treatment start dates during calendar year 2002 were eligible for inclusion. From these, we randomly selected every second MDR-TB patient and every $13^{\text {th }}$ non MDR-TB patient from the TB registry, starting from a random set point. These were included where basic and comparable data points were available; where such information was insufficient, we selected the next eligible subject from the registry.

We trained public health clinic staff within the NTAP to abstract clinical and outcome data from patient records using a standard methodology and data collection instrument. Demographic, clinical, and health system utilization data were abstracted. These included gender, age, geographic location, treatment delivery type, duration, and current treatment outcomes. Outcome measures were identified from the clinical impressions reflected in the patient records and were aggregated into three categories--cured, death, or not cured (included treatment failure and default). Patients with a history of prior treatment were also identified. Health system utilization data abstracted included duration of antituberculosis treatment in days; the type and number of outpatient clinical encounters; duration of inpatient treatment; and the other medical supplies, services, or procedures consumed during anti-tuberculosis therapy, such as anti-tuberculosis drugs, laboratory tests, and imaging services. Susceptibility testing in Latvia is standard during diagnosis, and we identified resistance on that basis [20]. Data on extensively drug resistant (XDR) TB and quinolone resistance was not captured.

Cost data were obtained by study staff from clinic and other administrative records. Treatment cost was measured as a proportional share of the total annualized cost for all

Table 1 Comparison of tuberculosis morbidity and mortality between various countries in 2009

\begin{tabular}{lrrrrrr}
\hline & Latvia & Estonia & Lithuania & Romania & Ukraine & USA \\
\hline Population (millions) & 2.205 & 1.283 & 3.536 & 21.905 & 75.135 & 313.232 \\
\hline Life expectancy (yrs) & 72.68 & 73.33 & 75.34 & 73.98 & 68.58 & 78.37 \\
\hline Death rate (deaths/1,000) & 13.6 & 13.55 & 11.33 & 11.81 & 15.74 & 8.38 \\
\hline TB incidence & 1,100 & 450 & 2,600 & 27,000 & 59,000 & 14,000 \\
\hline TB rate per 100,000 pop & 49.89 & 35.07 & 73.53 & 123.26 & 130.72 \\
\hline MDR-TB incidence & 131 & 86 & 322 & & 3,482 & $1,437(41 \%)$ \\
\hline New cases (\% of total MDR) & $83(63 \%)$ & $54(63 \%)$ & $114(35 \%)$ & & $2,045(59 \%)$ \\
\hline Previously treated (\% of total MDR) & $48(37 \%)$ & $32(37 \%)$ & $208(65 \%)$ & & $3,771(11 \%)$ & $706(6 \%)$ \\
\hline Number of TB cases with +HIV (\%) & $73(9 \%)$ & $39(10 \%)$ & $14(\mathrm{NA})$ & & 11,500 & 6,700
\end{tabular}

Source: World Health Organization (WHO). Global Health Observatory Data Repository. Found at http://www.who.int/tb/search/en/index.html. 2009. 
infrastructure, wages, utilities, supplies, and other goods and services consumed by inpatient and outpatient services. Outpatient service costs were denominated by encounter, e.g. the cost of one directly observed therapy visit for one patient. Inpatient care cost was denominated by patient day, and was estimated in a similar fashion to costs for outpatient care. Where staff, facilities, or other resources were shared between tuberculosis and other care, the cost of tuberculosis care was estimated based on the proportion of the resource consumed by tuberculosis care. For instance, the cost of facility infrastructure assigned to tuberculosis care was estimated as a function of the physical area used in that care. Costs were converted from the Lat to 2002 U.S. dollars (USD) for analysis and report.

Estimates of cost and outcomes are limited to those incurred by the public health system during the course of tuberculosis treatment. We did not attempt to estimate the economic costs or value associated with personal health losses or gains, such as acute illness, death, or cure. We did not estimate societal or other nonhealth system costs such as wage or other personal losses to a patient during treatment. Cost estimations that occur during the course of treatment are near term, representing periods of generally two years or less, and we did not discount or adjust these for time.

We used multivariate regression analysis to identify healthcare cost and utilization patterns associated with a diagnosis of MDR-TB. Negative binomial regression was used to model utilization outcomes (number of hospital days, clinic visits, specialist visits, $\mathrm{x}$-rays and c computed tomography $(\mathrm{CT})$ ) adjusting for vital status, sex, age, and cured status. Linear regression analysis was used to examine inpatient, outpatient, prescription medication and overall costs in USD adjusting for type of TB infection, sex, age, and outcome. Robust standard errors are reported and all p-values were two-tailed. A p-value $<0.05$ was considered statistically significant. All data, cost, and outcome measures are reported in the aggregate, and no personal or patient identifiers were collected, retained or reported. This program evaluation was determined to be nonhuman subject's research by both the Office of the Associate Director for Science, U.S. Centers for Disease Control and Prevention, and by the University of North Texas Health Science Center's Office for the Protection of Human Subjects; these determinations were provided, reviewed, and approved by program personnel within the NTAP.

\section{Results}

We analyzed NTAP data from 92 MDR-TB and 54 non MDR patients beginning treatment in 2002. Patients with MDR-TB were more commonly male ( $78 \%$ vs. $63 \%$, $\mathrm{p}$-value $=.05)$, middle aged ( $89 \%$ vs. $74 \%$, aged $25-64$, $\mathrm{p}$-value $=.019)$, and enjoyed lower cure rates $(71 \%$ vs. $91 \%, \mathrm{p}$-value $=.006)$ relative to those without (Table 2).
Most 67\% (61/92) MDR-TB patients had recorded prior tuberculosis treatment. No non MDR TB patients in our sample had prior tuberculosis treatment history (Table 2).

Patients with MDR-TB consumed more specialist visits, pharmaceuticals, laboratory services, $\mathrm{x}$-rays, CT scans, and inpatient days than those with non MDR-TB, with average treatment cost 4 times greater (mean $=28,821$ vs. 8,408 USD, p-value<.001) (Table 2). Outpatient care costs were not significantly different, but MDR-TB patients averaged almost an entire year longer as hospital inpatients than non MDR-TB patients (mean $=481$ vs. 115 days, $\mathrm{p}$-value $<.001$ ) at higher average cost (mean $=25,000$ vs. 6,900 USD, p-value<.001). Medication cost for MDR-TB patients averaged 35 times (2,146 vs. 61 USD, p-value<.001) that of others.

Table 2 Characteristics of non MDR and and MDR-TB patients, healthcare utilization, and cost (standard errors in parentheses), Latvia 2002

\begin{tabular}{|c|c|c|c|}
\hline & $\begin{array}{c}\text { MDR-TB } \\
(n=9)\end{array}$ & $\begin{array}{c}\text { Non MDR-TB } \\
(n=54)\end{array}$ & $p$-value \\
\hline \multicolumn{4}{|l|}{ Vital status, \% } \\
\hline Dead & 6.6 & 3.7 & .461 \\
\hline Alive & 93.4 & 96.3 & .461 \\
\hline Age, years & $44.1(1.3)$ & $42.6(2.5)$ & .558 \\
\hline \multicolumn{4}{|l|}{ Age group, \% } \\
\hline$<25$ & 6.6 & 14.8 & .105 \\
\hline $25-64$ & 89.0 & 74.1 & .019 \\
\hline 65 or over & 4.4 & 11.1 & .123 \\
\hline \multicolumn{4}{|l|}{ Sex, \% } \\
\hline Male & 78.0 & 63.0 & .050 \\
\hline Female & 22.0 & 37.0 & .050 \\
\hline \multicolumn{4}{|l|}{ Treatment success, \% } \\
\hline Cured & 71.4 & 90.7 & .006 \\
\hline Not cured & 28.6 & 9.3 & .006 \\
\hline
\end{tabular}

\begin{tabular}{|c|c|c|c|}
\hline \multicolumn{4}{|l|}{ Previous treatment, \# (\%) } \\
\hline None & $31(33 \%)$ & $54(100 \%)$ & $<.001$ \\
\hline First-line & $55(60 \%)$ & 0 & $<.001$ \\
\hline Second-line & $6(7 \%)$ & 0 & $<.001$ \\
\hline ospital days, \# & $481.4(25.0)$ & $114.9(12.6)$ & $<.001$ \\
\hline inic visits, \# & $73.7(13.4)$ & $70.4(9.2)$ & .859 \\
\hline Specialist visits, \# & $11.0(1.3)$ & $5.1(.6)$ & $<.001$ \\
\hline utum smears, \# & $35.9(1.3)$ & $12.9(.7)$ & $<.001$ \\
\hline utum cultures,\# & $33.9(1.4)$ & $10.4(.6)$ & $<.001$ \\
\hline rays, \# & $14.1(.8)$ & $6.4(.5)$ & $<.001$ \\
\hline$C T$, \# & $1.0(.1)$ & $.5(.1)$ & .011 \\
\hline \multicolumn{4}{|l|}{ ealth care costs, 2002 USD \$ } \\
\hline Inpatient & $\$ 25,004(1,301)$ & $\$ 6,904(759)$ & $<.001$ \\
\hline Outpatient & $\$ 1,672(303)$ & $\$ 1,443(188)$ & .587 \\
\hline Prescription medication & $\$ 2,146(115)$ & $\$ 601(3)$ & $<.001$ \\
\hline Total treatment & $\$ 28,821(1,245)$ & $\$ 8,408(649)$ & $<.001$ \\
\hline
\end{tabular}


Table 3 Multivariate regression adjusted total cost of treatment by provider setting, 2002 \$SD (N=145)

\begin{tabular}{|c|c|c|c|c|}
\hline & Inpatient & Outpatient & Prescription medication & Overall \\
\hline \multicolumn{5}{|l|}{ Type of infection } \\
\hline Non MDR-TB & Ref. & Ref. & Ref. & Ref. \\
\hline MDR-TB & $\$ 18,729(15,563,21,893) * * *$ & $\$ 592(-192,1,375)$ & $\$ 2,199(1,956,2,442)^{* * *}$ & $\$ 21,520(18,751,24,288)^{* * *}$ \\
\hline \multicolumn{5}{|l|}{ Sex } \\
\hline Female & Ref. & Ref. & Ref. & Ref. \\
\hline Male & $\$ 5,002(1,362,8,641) * *$ & $-\$ 834(1,859,191)$ & $\$ 228(-41,497)$ & $\$ 4,395(1,358,7,433)^{* *}$ \\
\hline \multicolumn{5}{|l|}{ Age group } \\
\hline$<25$ & Ref. & Ref. & Ref. & Ref. \\
\hline $25-64$ & $\$ 4,310(-1,294,9,914)$ & $-\$ 436(-1,781,909)$ & $\$ 224(-214,661)$ & $\$ 4,097(-987,9,181)$ \\
\hline$>=65$ & $\$ 6,244(-993,13,480)$ & $-\$ 1,233(-2,666,199)$ & $30(-517,577)$ & $\$ 5,040(-1,738,11,818)$ \\
\hline \multicolumn{5}{|l|}{ Outcome of treatment } \\
\hline Not cured & Ref. & Ref. & Ref. & Ref. \\
\hline Cured & $\$ 7,707(3,044,12,371)^{* * *}$ & $\$ 1,305(328,2,282) * *$ & $\$ 923(530,1,315)^{* * *}$ & $\$ 9,935(5,370,14,500)^{* * *}$ \\
\hline \multicolumn{5}{|l|}{ Vital status } \\
\hline Alive & Ref. & Ref. & Ref. & Ref. \\
\hline Dead & $-\$ 4,070(-12,424,4,283)$ & $-\$ 124(-1,105,857)$ & $-\$ 65(-919,788)$ & $-\$ 4,259(-13,215,4,696)$ \\
\hline$R^{2}$ & .51 & .10 & .67 & .63 \\
\hline $\mathrm{N}$ & 145 & 145 & 145 & 145 \\
\hline
\end{tabular}

Table 3 presents results from multivariate regression analysis of healthcare costs adjusting for type of TB infection, sex, age, and outcome. Healthcare costs included inpatient, outpatient, prescription medication and overall costs. Patients with MDR-TB were predicted to incur an additional 18,729 USD in inpatient treatment costs and 2,199 USD additional prescription medication costs compared to non MDR TB patients.

Multivariate negative binomial regression was used to examine healthcare utilization adjusting for sex, age and cured status. Estimated number of hospital days, clinic visits, specialist visits, X-rays, and CT for MDR and non MDR-TB patients adjusting for confounding factors are provided in Table 4. MDR TB patients are predicted to have spent one extra year in inpatient treatment compared to non MDR patients (475.3 vs. 110.2, p-value<.001). Similarly, MDR TB involved a higher number of specialist

Table 4 Adjusted health care utilization by MDR-TB diagnosis $(n=145) *$

\begin{tabular}{rccc}
\hline & $\begin{array}{c}\text { Non MDR (n=54) } \\
\text { Mean (CI) }\end{array}$ & $\begin{array}{c}\text { MDR (n=92) } \\
\text { mean (CI) }\end{array}$ & $\begin{array}{r}\text { p-value of } \\
\text { difference }\end{array}$ \\
\hline Hospital days, \# & $110.2(86.1,134.4)$ & $475.3(427.9,522.6)$ & $<.001$ \\
\hline Clinic visits, \# & $53.3(35.3,71.3)$ & $67.9(42.5,93.3)$ & .357 \\
\hline Specialist visits, \# & $4.3(3.3,5.4)$ & $11.0(8.6,13.3)$ & $<.001$ \\
\hline X-rays, \# & $6.4(5.4,7.4)$ & $13.9(12.4,15.5)$ & $<.001$ \\
\hline CT, \# & $0.5(0.4,0.7)$ & $1.0(.8,1.2)$ & .003
\end{tabular}

* Negative binomial regression adjusts for vital status, sex, age and cured status. Chi-square test used to calculate $p$-values. visits (11.0 vs. 4.2, $\mathrm{p}$-value<.001), $\mathrm{x}$-rays (13.9 vs. 6.4, $\mathrm{p}$-value<.003) and CT $(1.0$ vs. .5, p-value=.003) than non MDR-TB.

There was not a significant increase in clinic visits for MDR compared to non MDR TB patients, however. This may be explained by longer hospitalizations for MDR patients.

\section{Discussion}

The growing presence of MDR-TB in Latvia presented clinical, administrative, and policy challenges related to its disproportionate impact on patient health and on health system costs. We analyzed healthcare, cost and health outcomes among Latvian TB patients to identify their interaction with treatment failure and its consequences. Our findings suggest the value of public investments that prioritize, sustain and enhance effective efforts against tuberculosis.

Prevention is a cornerstone of sustained and consistent public health infrastructure [20-24]. Drug resistance in TB patients is preventable, and begins with prompt and adequate treatment of susceptible $M$. tuberculosis. Even so, we found indications of treatment failure in our sample contributing to primary and acquired resistance. Prior treatment with first line and second line drugs was reported for $60 \%$ and $7 \%$ of study subjects with currently diagnosed MDR-TB. In contrast, there was no record of prior TB treatment for any of the non MDR-TB patients, who enjoyed better health outcomes and were treated at less than $1 / 3$ the cost. 
Multivariate linear regression revealed drug resistance as a robust predictor for the total cost for TB treatment and predicts where those costs fall most heavily. We found medication for treatment of MDR-TB medications to be the single largest contributor to its excess cost. The average duration of MDR-TB treatment among our cohort was almost twice that of non MDR-TB patients. Considering partial and incomplete treatments due to death, failure, and loss to follow-up, our data indicated that MDR-TB treatment averaged 293 days per patient-more than twice as long as the 147 days of treatment for the average non MDR-TB patient (results not shown). Lengthy treatment of MDR-TB consumed greater quantities of medication relative to that of other patients, at a much higher cost per dose for that medication.

These finding suggest a tangible value to tuberculosis control infrastructure that achieves treatment adherence and completion and controls development of resistance [25-28]. Our sample represents roughly 50\% of Latvia's MDR-TB incidence during our study period; we found most (61 of 92) of these had prior TB treatment. Had original treatment been sufficiently effective to prevent progression to MDR-TB, over $\$ 1,313,000$ in health system savings-as well as health benefits from preventing such serious illness--might have been realized. Estimates based on our findings suggest every $10 \%$ reduction in multidrug-resistance nationwide would avert costs greater than \$250,000 USD annually.

This analysis has limitations. Although data represents approximately one half of patients identified during 2002 with MDR-TB and about $7.5 \%$ of those with non MDR-TB, our sample size remained relatively small and lacked sufficient power to identify significant differences in more finely stratified analyses. To preserve analytical power, we aggregated the treatment outcomes in broader categories; however reported cure rates for newly incident TB in 2002 remained consistent with those reported elsewhere [29]. Case finding in Latvia remains passive, as persons with tuberculosis become known only after seeking care, often with more advanced or debilitating illness [19]. It is plausible that ascertainment bias among the non MDR-TB overrepresents patients with more severe and costly illness, as they were known to the healthcare system through their inand outpatient medical care. Although such sampling bias may overestimate the cost of care and the severity of outcomes, this still allows the most conservative estimate of these impacts and changes only the magnitude, not the direction, of our findings. Duration of outpatient care was not recorded, and assessment of treatment success was dichotomous-success or not. We were therefore unable to evaluate the effects on cost and outcome of partial treatments, to identify the rate of medical system utilization as a function of time, or to denominate outpatient care as a cost per day. Our data was not longitudinal; hence allowing only point estimates. We did not have sufficient sample size to allow a robust stratified analysis. It is likely that we underestimate the actual value of successful control of MDR-TB, and may undervalue the potential benefits of prevention. We reported only treatment costs incurred by the health system. A more broad estimate, such as from a societal perspective, might include many elements we did not. These might include measures of individual health losses from morbidity and mortality among patients or their contacts; other public health infection control activities such as contact tracing; or of resources consumed outside of the public health system [13,14,30-32]. It is also important to note that in 2002, Latvia procured second-line drugs through a mechanism of the Green Light Committee that reduced cost to the program [33]. As such, the data regarding drug cost of MDR-TB maybe artificially low.

These limitations do not compromise our conclusions, however. We were able to identify patterns that suggest an association between treatment or program failure and multi-drug resistance. We identified the cost of cure for TB patients, and we identified the cost and some clinical outcome differentials between non MDR and MDR-TB patient care by major categories. We estimated the opportunity costs associated with MDR-TB from the public health setting perspective, and by doing so allow a plausible estimate of the lower bound value of reduced treatment or program failure.

Political boundaries are no protection from the dangers of MDR-TB to an international community. The effective control and prevention of acquired resistance represents an opportunity for health preservation well beyond the borders of Latvia. Global health protections require a consistent and united tuberculosis control infrastructure, however, and the value of these may not be apparent to health policy decision makers. We have clearly and conservatively identified the opportunity costs associated with the public treatment of MDRTB patients in Latvia. This may allow a more clear judgment of the value of its control, and may be a critical component in the public fight against this dangerous disease.

\section{Competing interests}

The authors declare that they have no competing interests.

\section{Authors' contributions}

$\mathrm{VL}, \mathrm{TH}, \mathrm{KC}, \mathrm{AC}, \mathrm{PM}$, and $\mathrm{VR}$ collaborated to conceive the study and to direct data collection and management. TM and FW designed and conducted the analysis and led its interpretation. TM led the drafting and refinement of the manuscript with the participation of FW, VL, TH, KC, AC, PM, and VR. All authors read and approved the final manuscript.

\section{Acknowledgments}

The authors gratefully acknowledge the support of the International Research and Programs Branch of U.S. Centers for Disease Control and Prevention's Division of Tuberculosis, which provided resources and that made this work possible. In addition, they acknowledge the valuable 
intellectual and other contributions made by Drs. Zachary Goode and Erin Carlson of the University of North Texas Health Science Center, and thank Drs. Peter Cegielski, Eugene McCray and Phil LoBue for their critical review.

\section{Disclaimer}

The findings and conclusions in this report are those of the authors and do not necessarily represent the views of the US Centers for Disease Control and Prevention.

\section{Author details}

${ }^{1}$ University of North Texas Health Science Center at Fort Worth, School of Public Health, Fort Worth, TX, USA. ${ }^{2}$ State Agency Infectology Center of Latvia, Riga, Latvia. ${ }^{3}$ Division of HIV/AIDS Prevention, Centers for Disease Control and Prevention, Atlanta, GA, USA. ${ }^{4}$ Division of Tuberculosis Elimination, Centers for Disease Control and Prevention, Atlanta, GA, USA. ${ }^{5}$ World Health Organization Collaborative Center for Research and Training in Management of Multidrug-resistant Tuberculosis, State Agency Infectology Center of Latvia, Riga, Latvia.

Received: 5 December 2012 Accepted: 11 April 2013 Published: 17 April 2013

\section{References}

1. Cohn DL, Catlin BJ, Peterson KL, Judson FN, Sbarbaro JA: A 62-dose, 6-month therapy for pulmonary and extrapulmonary tuberculosis. A twice-weekly, directly observed, and cost-effective regimen. Ann Intern Med 1990, 112:407-415.

2. Dutt AK, Moers D, Stead WW: Short-course chemotherapy for tuberculosis with mainly twice-weekly isoniazid and rifampin community physicians' seven-year experience with mainly outpatients. Am J Med 1984, 77:233-242

3. Centers for Disease Control and Prevention: Outbreak of multi-drug resistant tuberculosis-Texas, California, and Pennsylvania. MMWR 1990, 39(22):369-372. Jun 8.

4. Dixon W, Stradling P, Wooten I: Outpatient P.A.S. therapy. Lancet 1957, 2:871-872.

5. Davis MS: Predicting noncompliant behavior. J Health Soc Behav 1967, 8:265-271.

6. Addington WW: Patient compliance: the most serious remaining problem in the control of tuberculosis in the United States. Chest 1979, 76:741-743

7. Fox W: Compliance of patients and physicians: experience and lessons from tuberculosis-II. Br Med J (Clin Res Ed) 1983, 287:101-105.

8. Cramer JA, Mattson RH, Prevey ML, Scheyer RD, Ouellette VL: How often is medication taken as prescribed? A novel assessment technique.[see comment][erratum appears in. JAMA 1989, 262(11):1472. JAMA. 1989:261:3273-3277.

9. Sumartojo E: When tuberculosis treatment fails. A social behavioral account of patient adherence. Am Rev Respir Dis 1993, 147:1311-1320.

10. World Health Organization: Anti-tuberculosis Drug Resistance in the World: the WHO/IUATLD Global Projection Anti-Tuberculosis Drug Resistance Surveillance. Report No. 4. Prevalence and Trends. Geneva: WHO; 2008.

11. World Health Organization: Guidelines for the Programmatic Management of Drug-Resistant Tuberculosis: Emergency Update 2008. Geneva: World Health Organization; 2008.

12. Muennig P: Designing and Conducting Cost-Effectiveness Analyses in Medicine and Health Care. San Francisco: Jossey-Bass; 2002

13. Miller TL, et al: The societal cost of tuberculosis. Ann Epidemiol 2010, 20(1):1-7.

14. Weis SE, Miller TL, et al: Comprehensive cost description of tuberculosis care. Int J Tuberc Lung Dis 2005, 9(4):467-470.

15. O'Brien R: The treatment of tuberculosis. In Tuberculosis: A Comprehensive International Approach, Volume 66. Edited by Reichman L, Hershfield E. New York: Marecel Dekker; 1993:207-240

16. Kochi A, Vareldzis B, Styblo K: Multidrug-resistant tuberculosis and its control. Res Microbiol 1993, 144:104-110.

17. Multidrug and extensively drug-resistant TB (M/XDR-TB): 2010 global report on surveillance and response. Geneva: World Health Organization; 2010.

18. Brown H: Looking to the future in Latvia. Lancet 2004, 364(9451):2083-6.
19. Leimane V, Dravniece G, Riekstina V, Sture I, Kammerer S, Chen MP, Skenders G, Holtz TH: Treatment outcome of multidrug/extensively drugresistant tuberculosis in Latvia, 2000-2004. Eur Respir J 2010, 36:584-593.

20. Zignol M, Van Gemert W, Falzon D, Sismanidis C, Glaziou P, Floyd K, Raviglione M: Surveillance of anti-tuberculosis drug resistance in the world: an updated analysis, 2007-2010. Bull World Health Organ 2012, 90(2):111-119D.

21. World Health Organization: Global tuberculosis control: Surveillance, planning, financing. WHO report 2005. Geneva: World Health Organization; 2005.

22. Reichman LB: The U-shaped curve of concern. Am Rev Respir Dis 1991, 144(4):741-2.

23. Wallace D: 'Benign neglect' of inner city led to TB epidemic. Nature 2000, 407:559.

24. Bayer R, Wilkinson D: Directly observed therapy for tuberculosis: History of an idea. Lancet 1995, 345:1545-1548.

25. Goble M, Iseman MD, Madsen LA, Waite D, Ackerson L, Horsburgh CR Jr: Treatment of 171 patients with pulmonary tuberculosis resistant to isoniazid and rifampin. N Engl J Med 1993, 328:527-532.

26. Geiter $L(E d)$ : Ending Neglect: The Elimination of Tuberculosis in the United States. Washington, D.C.: National Academy Press; 2000.

27. Navin TR, McNabb SJ, Crawford JT: The continued threat of tuberculosis. Emerg Infect Dis 2002, 8:1187.

28. American Thoracic Society, Centers for Disease Control and Prevention, and Infectious Diseases Society of America: Controlling tuberculosis in the United States. MMWR 2005, 54:1-81. Accessed 11/30/2005

29. Leimane $V$, Leimans J: Tuberculosis control in Latvia: integrated DOTS and DOTS-plus programmes. Euro Surveill 2006, 11(3):29-33.

30. Pasipanodya JG, McNabb SJN, Hisenrath PE, Bae S, Lykens K, Vecino E, Munguia G, Miller TL, Weis SE, Drewyer G: Pulmonary impairment after tuberculosis and its contribution to TB burden. BMC Public Health 2010, 10:259.

31. Miller $\mathrm{TL}$, et al: Personal and societal health quality lost to tuberculosis. PLoS One 2009, 4(4):e5080. doi:10.1371/journal.pone.0005080.

32. Pasipanodya JG, Miller TL, et al: Pulmonary impairment after tuberculosis. Chest 2007, 131:1817-1824.

33. The New Global Framework to support expansion of MDR-TB services and care. Geneva: World Health Organization; 2012. Available at: http://www.who.int/ tb/challenges/mdr/greenlightcommittee/en/index.html.

doi:10.1186/1478-7547-11-9

Cite this article as: Miller et al:: The value of effective public tuberculosis treatment: an analysis of opportunity costs associated with multidrug resistant tuberculosis in Latvia. Cost Effectiveness and Resource Allocation 2013 11:9.

\section{Submit your next manuscript to BioMed Central and take full advantage of:}

- Convenient online submission

- Thorough peer review

- No space constraints or color figure charges

- Immediate publication on acceptance

- Inclusion in PubMed, CAS, Scopus and Google Scholar

- Research which is freely available for redistribution 